\title{
Novel Surface Coating Materials Based on Castor Oil-Epoxy Resin Reaction Products
}

\author{
BHAVDEEP K. PATEL ${ }^{*}$, HASMUKH S. PATEL and SHASHANK N. DESAI \\ Department of Chemistry, Sardar Patel University, Vallabh Vidyanagar-388120, \\ Gujarat, India \\ patelbhavdeep82@yahoo.com
}

Received 10 June 2012 / Accepted 7 July 2012

\begin{abstract}
Reactions of castor oil (CO) with varying mole ratios of commercial epoxy resin of diglycidyl ether of bisphenol-A (i.e. DGEBA) were carried out by adding triethyl amine (TEA) as a base catalyst. The resultant products were designated as castor oil-epoxy resin (COERs) products and characterized by physical, chemical and IR spectral study. The surface coating systems based on alkyd-COERs and cyclohexanone-formaldehyde resin-COERs (CHF-COERs) blends have been prepared and characterized by mechanical and chemical properties.
\end{abstract}

Keywords: Epoxy resin, DGEBA, Castor oil-epoxy resin, COERs, Alkyd resin, Cyclohexanoneformaldehyde resin

\section{Introduction}

Castor oil known preliminary for its medicinal use as a cathartics, is now also used primarily as an industrial raw material for the preparation of chemical derivatives used in coatings, urethanes derivatives, surfactants, dispersant, cosmetics and lubricants etc. Castor oil serves raw material for the manufacture of number of industrial products ${ }^{1}$. Castor oil and its many derivatives have been successfully used for at least twenty years as a polyols for the preparation of polyurethanes, particularly in the preparation of polyurethane coatings, adhesives and casting compounds, increase hydrolytic stability and electrical insulating properties. Castor oil is also used in coating application, as surfactants, as lubricants and in textile industries ${ }^{2-5}$.

Epoxy resins are versatile resins having wide range of properties such as adhesion to substrate, corrosion resistance and high tensile, flexural and compressive strengths. Because of the versatile properties exhibited by epoxy resin it has found number of applications ${ }^{6,7}$.

Hence, it was thought interesting to study reaction products of castor oil with epoxy resin (DGEBA) in order to obtain good coating composition with alkyd resin and CHF resin. Recently some work in this direction from our laboratory has been also reported ${ }^{8}$. The present article comprises synthesis and characterization of castor oil-epoxy resin products and their blends with alkyd resin and cyclohexanone-formaldehyde resin (CHF). 


\section{Experimental}

Castor oil was purchased form local market. Epoxy resin (i.e. DGEBA) was obtained form Atul Industries Limited (Valsad, India), Alkyd resin was procured from pacific paints (V.U.Nagar, India), cyclohexanone-formaldehyde resin and other chemicals were obtained from Chiti-Chem Corp. (Baroda, India).

\section{Preparation of castor oil-epoxy resin products (COERs)}

The castor oil-epoxy resin products (COERs) were prepared easily by using method reported in our earlier communication ${ }^{8}$. The method for preparation of castor oil-epoxy resin products (COERs) is given briefly as follows.

Castor oil (0.268 mole) was taken in to a three necked flask equipped with a mechanical stirrer and placed in a water bath where temperature was maintained at 70-80 ${ }^{\circ} \mathrm{C}$. Under continuous stirring desired amount of epoxy resin (Table 1 ) was added with $0.05 \%$ of triethyl amine (added as a base catalyst). At the regular interval of time, a sample was withdrawn from the reaction mixture using siphoning device and test was performed for the negative epoxy resin using ${ }^{9}$. When the sample showed the negative test for the epoxy resin reaction was stopped and product was allowed to cool at room temperature. The resultant products are designated as castor oil-epoxy resin (COERs) products, after which it was subjected to preliminary characterization. The varying type of mole ratios of epoxy resin used for the preparation of COERs and physical properties of resultant products (COERs) are given in Table 1. Chemical characterizations of resultant products (COERs) are given in Table 2. The IR spectrum for castor oil and COER-1 are shown in Figure 1 which will indicates that completion of the reaction.

Table 1. Synthesis and physical properties of COERs

\begin{tabular}{|c|c|c|c|c|c|}
\hline \multicolumn{2}{|c|}{$\begin{array}{c}\text { Mole of } \\
\text { reactants taken }\end{array}$} & \multirow{2}{*}{ Designation } & \multirow{2}{*}{ Appearance } & \multirow{2}{*}{$\begin{array}{c}{ }^{*} \text { Viscosity in } \\
\text { sec. }\end{array}$} & \multirow{2}{*}{$\begin{array}{l}\text { Sp. } \\
\text { gravity in } \\
\text { g/cc }\end{array}$} \\
\hline Castor oil & $\begin{array}{l}\text { Epoxy } \\
\text { resin }\end{array}$ & & & & \\
\hline 0.268 & 0.134 & COER-1 & $\begin{array}{l}\text { Pale yellow } \\
\text { and clear }\end{array}$ & 135 & 0.98 \\
\hline 0.268 & 0.268 & COER-2 & $\begin{array}{l}\text { Dark yellow } \\
\text { and clear }\end{array}$ & 240 & 1.01 \\
\hline 0.268 & 0.402 & COER-3 & $\begin{array}{c}\text { Brownish } \\
\text { yellow and } \\
\text { clear }\end{array}$ & 290 & 1.05 \\
\hline
\end{tabular}

"Viscosity time was measured using ford cup type " $B$ " IV at room temperature

Table 2. Chemical properties of COERs

\begin{tabular}{ccccc}
\hline $\begin{array}{c}\text { Type of } \\
\text { COER }\end{array}$ & $\begin{array}{c}\text { Hydroxyl } \\
\text { number }\end{array}$ & $\begin{array}{c}\text { Hydroxyl value in } \\
\text { mg of KOH/g }\end{array}$ & $\begin{array}{c}\% \\
\text { Hydroxyl }\end{array}$ & $\begin{array}{c}\text { Number of unsaturation } \\
\text { per molecule }\end{array}$ \\
\hline COER-1 & 3 & 145 & 4.56 & 3 \\
COER-2 & 3 & 130 & 3.89 & 3 \\
COER-3 & 3 & 113 & 3.37 & 3 \\
\hline
\end{tabular}




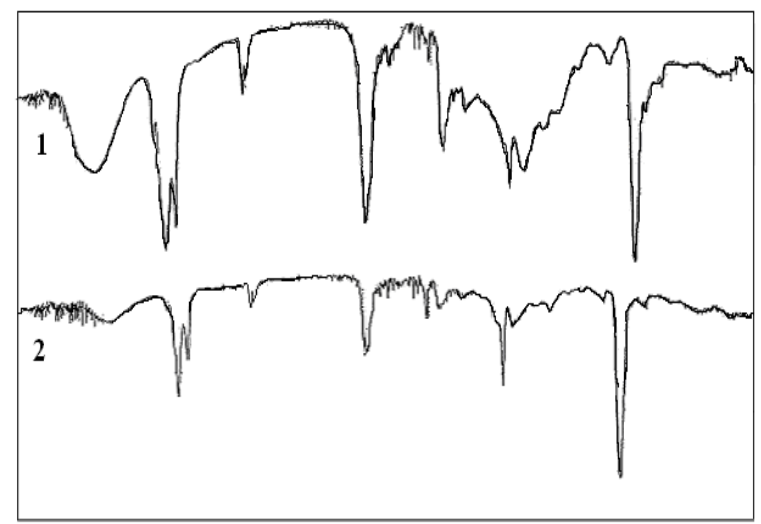

Figure 1. IR Spectra of (1) Castor oil and (2) COER-1

\section{Preparation of alkyd-COERs and CHF-COERs blends}

To prepare alkyd-COERs and CHF-COERs blends, a simple method involving physical mixing was employed, both can be prepared by same method as described below: Three necked flask equipped with a mechanical stirrer, alkyd resin was charged and under continuous stirring desired amount of specific COERs (Table 3) were added gradually over the period of half an hour. Upon the completion of addition the reaction mixture was stirred for an hour after which it was kept aside in a cylindrical glass container for over night to check any tendency of separation of the two layers. In neither case separation of the two layers was observed.

Table 3. Preparation of films from alkyd-COERs and CHF-COERs blends

\begin{tabular}{|c|c|c|c|c|c|c|}
\hline 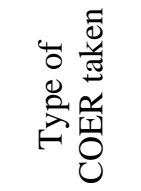 & 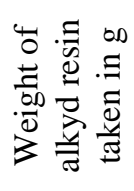 & 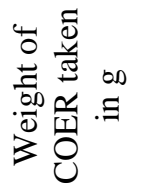 & 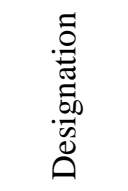 & 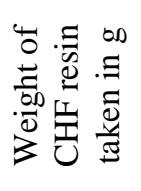 & $\begin{array}{l}\text { Weight of } \\
\text { COER } \\
\text { taken in g }\end{array}$ & Designation \\
\hline \multirow{4}{*}{ COER-1 } & \multirow{3}{*}{100} & 10 & AC-101 & \multirow{3}{*}{100} & 10 & CHFC-101 \\
\hline & & 20 & AC-201 & & 20 & CHFC-201 \\
\hline & & 30 & AC-301 & & 30 & CHFC-301 \\
\hline & \multirow{3}{*}{100} & 10 & AC-102 & \multirow{3}{*}{100} & 10 & CHFC-102 \\
\hline \multirow[t]{3}{*}{ COER-2 } & & 20 & AC-202 & & 20 & CHFC-202 \\
\hline & & 30 & AC-302 & & 30 & CHFC-302 \\
\hline & \multirow{3}{*}{100} & 10 & AC-103 & \multirow{3}{*}{100} & 10 & CHFC-103 \\
\hline \multirow[t]{2}{*}{ COER-3 } & & 20 & AC-203 & & 20 & CHFC-203 \\
\hline & & 30 & AC-303 & & 30 & CHFC-303 \\
\hline
\end{tabular}

Preparation of coating composition based on alkyd-COERs and CHF-COERs blends

To study the film properties of alkyd-COERs and CHF-COERs blends, the coating compositions of various blends were prepared in the following manner: $50 \mathrm{~g}$ of desired blend was taken in a $250 \mathrm{~mL}$ glass beaker. The driers lead octoate $(18 \% \mathrm{~Pb})$, cobalt octoate $(6 \% \mathrm{Co})$ and manganese octoate $(6 \% \mathrm{Mn})$ were added into it in the proportions of $0.5 \%, 0.05 \%$ and $0.05 \%$ respectively. The resultant blends were diluted with the suitable solvents to obtain a viscosity appropriate for application of the coating with a brush on clean mild steel panels. 


\section{Panel preparation}

The mild steel panels were first degreased in alkali solution and subsequently swabbed with xylene to remove any type of oily material or contaminant from the surface. After xylene has been evaporated the panels were coated by the above prepared coating composition.

\section{Film characterization}

The coated panels were examined for drying time, adhesion test, flexibility test, scratch hardness, pencil hardness, impact resistance and chemical resistance properties by standard methods. The results are given in Table 4, 5 and 6 respectively.

\section{Determination of drying time}

The mild steel panels were used to determine the air drying time of films of various blends. The panels were prepared in a similar manner written above and coating compositions were applied. The films were checked for 'surface dry' and 'tack-free dry' stages at regular interval of time. The results of drying time determination of various alkyd-COER and CHFCOER blends are given in Table 4.

\section{Determination of adhesion time}

Adhesion of films were determined by employing cross-hatch adhesion test and panels for the test were prepared exactly in a similar manner to that of drying time determination test. Cross-hatch adhesion test was carried out after $168 \mathrm{~h}$ of coating application. The results are given in Table 4.

Table 4. Properties of films prepared from alkyd-COERs and CHF-COERs blends

\begin{tabular}{cccccc}
\hline \multirow{2}{*}{ Type of COER } & \multirow{2}{*}{ Designation } & \multicolumn{2}{c}{ Drying time in minutes } & \multirow{2}{*}{ Adhesion } & \multirow{2}{*}{ Flexibility } \\
\cline { 3 - 4 } & & Surface dry & Tack-free dry & & \\
\cline { 3 - 4 } COER-1 & AC-101 & 100 & 240 & $\mathrm{~F}$ & $\mathrm{~F}$ \\
& AC-201 & 90 & 210 & $\mathrm{~F}$ & $\mathrm{P}$ \\
& AC-301 & 70 & 180 & $\mathrm{P}$ & $\mathrm{P}$ \\
COER-2 & AC-102 & 75 & 230 & $\mathrm{P}$ & $\mathrm{F}$ \\
& AC-202 & 60 & 215 & $\mathrm{~F}$ & $\mathrm{P}$ \\
& AC-302 & 55 & 190 & $\mathrm{P}$ & $\mathrm{P}$ \\
COER-1 & AC-103 & 55 & 210 & $\mathrm{P}$ & $\mathrm{P}$ \\
& AC-203 & 45 & 195 & $\mathrm{P}$ & $\mathrm{P}$ \\
& AC-303 & 40 & 175 & $\mathrm{P}$ & $\mathrm{P}$ \\
& CHFC-101 & 25 & 125 & $\mathrm{~F}$ & $\mathrm{~F}$ \\
& CHFC-201 & 23 & 115 & $\mathrm{~F}$ & $\mathrm{P}$ \\
& CHFC-301 & 20 & 110 & $\mathrm{P}$ & $\mathrm{P}$ \\
& CHFC-102 & 20 & 105 & $\mathrm{~F}$ & $\mathrm{P}$ \\
& CHFC-202 & 15 & 90 & $\mathrm{P}$ & $\mathrm{P}$ \\
& CHFC-302 & 12 & 80 & $\mathrm{P}$ & $\mathrm{P}$ \\
& CHFC-103 & 12 & 60 & $\mathrm{P}$ & $\mathrm{P}$ \\
& CHFC-203 & 10 & 55 & $\mathrm{P}$ & $\mathrm{P}$ \\
& CHFC-303 & 7 & 45 & $\mathrm{P}$ & $\mathrm{P}$ \\
\hline
\end{tabular}

\section{Determination of flexibility}

$P=$ Pass, $F=$ Fail

For the determination of flexibility, tinned mild steel panels were used. The coating compositions were applied and cured in the same manner as mentioned above. Flexibility 
test were carried out using mandrels having specific rod diameter. Generally 1/8 inch rod diameter mandrel was used and if film passed through 1/8 inch mandrel then it was said to be passed for the flexibility test. The results are given in Table 4 .

\section{Determination of scratch hardness}

In this method, a hand operated instrument was used in which test panel was kept on a sliding base with coated side upward and scratched under specific load with a needle which was in contact with film on test panel. The load was kept increasing till the film was scratched which was indicated by a light bulb that glows when film was scratched. The results are given in Table 5.

\section{Determination of pencil hardness}

In this method the use of pencil having different hardness are used. Sharp tipped pencils having hardness 4B (soft) and $6 \mathrm{H}$ (hard) were used to scratch the film. The pencil was held approximately at an angle of $45^{\circ}$ to the film and with uniform pressure pulled down over the length of the film. The test was repeated till a pencil with specific hardness was able to scratch the film and hardness off that pencil was reported as the pencil hardness test. The results are given in Table 5.

\section{Determination of impact resistance}

The coated test panels for impact resistance test were prepared in the same manner as described above. The test was carried out after $168 \mathrm{~h}$ of coating application. The coated panel was kept on a platform (coated side upward). The panel was then indented with an object of specific weight from the varying heights. The test was repeated by increasing the height from which the object falls till the film was cracked or detached. The results are given in Table 5.

Table 5. Mechanical properties of films prepared from alkyd-COERs and CHF-COERs blends

\begin{tabular}{ccccc}
\hline Type of COER & Designation & $\begin{array}{c}\text { Scratch hardness } \\
\text { in g }\end{array}$ & Pencil hardness & $\begin{array}{c}\text { Impact } \\
\text { resistance in·lb }\end{array}$ \\
\hline COER-1 & AC-101 & 2200 & $1 \mathrm{H}$ & 125 \\
& AC-201 & 2200 & $1 \mathrm{H}$ & 150 \\
& AC-301 & 2400 & $2 \mathrm{H}$ & 175 \\
COER-2 & AC-102 & 2600 & $3 \mathrm{H}$ & 150 \\
& AC-202 & 2600 & $4 \mathrm{H}$ & 150 \\
COER-3 & AC-302 & 2800 & $4 \mathrm{H}$ & 175 \\
& AC-103 & 2800 & $4 \mathrm{H}$ & 175 \\
& AC-203 & 3000 & $5 \mathrm{H}$ & 200 \\
COER-1 & AC-303 & 3000 & $5 \mathrm{H}$ & 225 \\
& CHFC-101 & 1000 & $1 \mathrm{H}$ & 25 \\
& CHFC-201 & 1200 & $1 \mathrm{H}$ & 25 \\
& CHFC-301 & 1200 & $2 \mathrm{H}$ & 50 \\
& CHFC-102 & 1400 & $1 \mathrm{H}$ & 50 \\
& CHFC-202 & 1600 & $2 \mathrm{H}$ & 50 \\
& CHFC-302 & 1800 & $3 \mathrm{H}$ & 75 \\
& CHFC-103 & 1800 & $3 \mathrm{H}$ & 75 \\
& CHFC-203 & 2100 & $4 \mathrm{H}$ & 100 \\
& CHFC-303 & 2200 & $4 \mathrm{H}$ & 100 \\
\hline
\end{tabular}




\section{Determination of chemical resistance properties}

The assessment of chemical resistance of the films to various chemicals, tinned mild steel panels were used which were prepared, coated and cured as mentioned above. The immersion method was utilized to assess the chemical resistance of films in which the panels were immersed vertically in the baths containing solutions of different chemicals with specific concentration at room temperature for the specific time period. Upon completion of the specified time period the panels were removed from the baths and allowed to dry before visual examination. The results of resistance against chemicals are given in Table 6 .

Table 6. Chemical resistances properties of films prepared from alkyd-COERs and CHFCOERs blends

\begin{tabular}{cccccc}
\hline $\begin{array}{c}\text { Type of } \\
\text { COER }\end{array}$ & Designation & $\begin{array}{c}\text { Acid } \\
\text { resistance } \\
5 \% \mathrm{HCl} \\
24 \mathrm{~h}\end{array}$ & $\begin{array}{c}\text { Alkali } \\
\text { resistance } \\
\text { 3\% NaOH } \\
2 \mathrm{~h}\end{array}$ & $\begin{array}{c}\text { Water } \\
\text { resistance } \\
\text { (Dist. Water) } \\
168 \mathrm{~h}\end{array}$ & $\begin{array}{c}\text { Solvent } \\
\text { resistance } \\
\text { Xylene } \\
168 \mathrm{~h}\end{array}$ \\
\hline COER-1 & AC-101 & 2 & 1 & 4 & 2 \\
& AC-201 & 3 & 2 & 4 & 3 \\
COER-2 & AC-301 & 4 & 3 & 5 & 4 \\
& AC-102 & 3 & 3 & 3 & 2 \\
& AC-202 & 4 & 2 & 4 & 3 \\
COER-3 & AC-302 & 5 & 3 & 5 & 4 \\
& AC-103 & 4 & 3 & 4 & 3 \\
& AC-203 & 5 & 4 & 5 & 4 \\
COER-1 & AC-303 & 5 & 5 & 5 & 5 \\
& CHFC-101 & 5 & 4 & 2 & 3 \\
& CHFC-201 & 5 & 4 & 3 & 3 \\
COER-2 & CHFC-301 & 5 & 5 & 3 & 4 \\
& CHFC-102 & 5 & 4 & 3 & 3 \\
& CHFC-202 & 5 & 5 & 3 & 4 \\
COER-3 & CHFC-302 & 5 & 5 & 4 & 4 \\
& CHFC-103 & 5 & 4 & 4 & 4 \\
& CHFC-203 & 5 & 5 & 5 & 5 \\
& CHFC-303 & 5 & 5 & 5 & 5 \\
\hline
\end{tabular}

$0=$ Film completely removed, $1=$ film removed and particularly cracked, $2=$ film partially cracked, $3=$ loss in gloss, $4=$ slight loss in gloss, $5=$ film largely unaffected

\section{IR spectral study of COERs products}

The IR spectrum of castor oil and all three COERs were scanned neat on $\mathrm{KBr}$ pellets. The IR spectrum of castor oil and COER-1 are shown in Figure 1. Interpretation of IR spectra of COERs reveals characteristic group frequencies. A broad band around $3500-3300 \mathrm{~cm}^{-1}$ can be assigned to intermolecular and intramolecular $H$-bonding in hydroxyl functionalities. Symmetrical stretching frequencies around $2930-2830 \mathrm{~cm}^{-1}$ due to aliphatic alkenes are observed. Well resolved sharp bands at $1746 \mathrm{~cm}^{-1}$ indicate the presence of carbonyl group of ester linkage in triglyceride structure. A series of bands at 1460, 1410 and $1366 \mathrm{~cm}^{-1}$ are observed due to asymmetric stretching vibrations of aliphatic moieties. A distinct but weak band around $1250 \mathrm{~cm}^{-1}$ and well resolved bands around 1180 and $1120 \mathrm{~cm}^{-1}$ can be ascribed to C-O linkages in castor oil molecule. Presence of distinct bands around 3020, 1500 and 
$960 \mathrm{~cm}^{-1}$ confirms the unsaturation, due to $\mathrm{C}-\mathrm{H}$ stretching, $\mathrm{C}=\mathrm{C}$ stretching and in-plane bending vibration frequencies respectively. In the IR spectrum of COERs band at $910 \mathrm{~cm}^{-1}$ is not observed which indicates the absence of epoxy group. Band due to aromatic rings are observed at their respective positions.

\section{Results and Discussion}

From Table 1 we can say that viscosity of COERs increases as the mole ratios of epoxy resin increases. Specific gravity of COERs increases as the amount of epoxy resin increases in COERs. From Table 2 we can say it is evident that the number of hydroxyl groups in all three COERs is 3 but hydroxyl value and \% hydroxyl decreases as the mole of epoxy resin increases. From the unsaturation test it is clear that the number of unsaturation per molecule in each COER is 3, which are same as in castor oil. It means that the reaction of epoxy resin has not occurred at double bond of castor oil.

From the results given in Table 4, it suggests that these films give good surface dry and good tack free dry properties. Also, from the results of adhesion test and flexibility we can say that these films give good adhesion and flexibility. Flexibility of all the films was measured by using 1/8" mandrel as per ASTM D 622. Excellent scratch hardness was obtained from the films, prepared from these blends. The pencil hardness and impact resistance are also good for such kind of films. Chemical resistance properties of all the films give satisfactory results.

\section{Conclusion}

Room temperature curing composition can be prepared easily and give satisfactory results. Castor oil and epoxy resin reaction products upon blending with other resin like alkyd and $\mathrm{CHF}$ resins gives good mechanical and chemical properties. From the results of these blends we can say that such kind of blends give good mechanical and chemical properties. Rather than using castor oil and epoxy resin reaction products individually their blends with alkyd and CHF resins found some importance.

\section{Acknowledgement}

The authors are thankful to Head of the chemistry department Dr. H. S. Patel for providing research facilities.

\section{References}

1 Lakshminarayana G J, Oil Technol Assoc., India, 1981, 13, 75.

2 Chandra S and Gupta R K, Pigment Resin Technol., 1994, 23(1), 7-9.

3 Patel D S, Nimavat K S and Vyas K B, Adv Appl Sci Res., 2011, 2, 558

$4 \quad$ Patel D S, Nimavat K S and Vyas K B, Der Chemica Sinica, 2011, 2, 118.

$5 \quad$ Chandra S and Gupta R K, Pigment Resin Technol., 1994, 23, 7

$6 \quad$ Shukla V, Pigment Resin Technol., 2006, 35(6), 353-357.

7 Samanta B C, Maity T, Dalai S and Banthia A K, Pigment Resin Technol., 2008, 37(1), 3-8.

8 Patel H S, Patel B K, Patel K B and Desai S N, Int J Poly Mater., 2010, 5925.

9 Roof W J, Scott J R and Pacitti J, Fibers, Films, Plastics and Rubbers, A Handbook of Common Polymers, Butterworths \& Co. Publishers Ltd., London, 1971. 